\title{
Review
}

Type 1 Diabetes

Diabetes Metab J 2021;45:312-325

https://doi.org/10.4093/dmj.2020.0171

pISSN 2233-6079 · eISSN 2233-6087

DIABET\&S \& METABOLISM JOURNAL

\section{Non-Insulin Antidiabetes Treatment in Type 1 Diabetes Mellitus: A Systematic Review and Meta- Analysis}

\author{
Xiaoling Cai ${ }^{1}$, Chu Lin ${ }^{1}$, Wenjia Yang ${ }^{1}$, Lin $\mathrm{Nie}^{2}$, Linong $\mathrm{Ji}^{1}$ \\ ${ }^{1}$ Department of Endocrine and Metabolism, Peking University People's Hospital, Beijing, \\ ${ }^{2}$ Department of Endocrine and Metabolism, Beijing Airport Hospital, Beijing, China
}

In order to evaluate the efficacy and side effects of the non-insulin antidiabetes medications as an adjunct treatment in type 1 diabetes mellitus (T1DM), we conducted systematic searches in MEDLINE, Embase, and the Cochrane Central Register of Controlled Trials for randomized controlled trials published between the date of inception and March 2020 to produce a systematic review and meta-analysis. Overall, 57 studies were included. Compared with placebo, antidiabetes agents in adjunct to insulin treatment resulted in significant reduction in glycosylated hemoglobin (weighted mean difference [WMD], $-0.30 \% ; 95 \%$ confidence interval [CI], -0.34 to $-0.25 \%$; $P<0.01$ ) and body weight (WMD, $-2.15 \mathrm{~kg} ; 95 \% \mathrm{CI},-2.77$ to $-1.53 \mathrm{~kg} ; P<0.01$ ), and required a significantly lower dosage of insulin (WMD, -5.17 unit/day; $95 \% \mathrm{CI},-6.77$ to -3.57 unit/day; $P<0.01$ ). Compared with placebo, antidiabetes agents in adjunct to insulin treatment increased the risk of hypoglycemia (relative risk [RR], 1.04; 95\% CI, 1.01 to $1.08 ; P=0.02)$ and gastrointestinal side effects (RR, $1.99 ; 95 \% \mathrm{CI}, 1.61$ to $2.46 ; P<0.01)$ in patients with T1DM. Compared with placebo, the use of non-insulin antidiabetes agents in addition to insulin could lead to glycemic improvement, weight control and lower insulin dosage, while they might be associated with increased risks of hypoglycemia and gastrointestinal side effects in patients with T1DM.

Keywords: Diabetes mellitus, type 1; Glycemic control; Hypoglycemia; Hypoglycemic agents

\section{INTRODUCTION}

Type 1 diabetes mellitus (T1DM) is characterized by destruction of the pancreatic $\beta$-cells [1], resulting in severely impaired or absent insulin secretion combined with abnormal $\alpha$-cell function, with excess glucagon in the fasting and postprandial state [2-4]. Tight glycemic control for T1DM patients recommended for its long-term effects on reducing the risk of microvascular complications [5] and macrovascular diseases [6,7]. However, intensive insulin therapy has its own limitations, which makes it difficult for patients with T1DM to achieve good glycemic control. Hypoglycemia is the main concern of intensive insulin therapy, with rates of severe hypoglycemia ranging between 115 and 320 events per 100 patient-years in patients with T1DM $[8,9]$. Intensive insulin therapy also contributes to weight gain and the obesity-related cardiometabolic consequences: hypertension, dyslipidemia, atherosclerosis, and subsequent cardiovascular events [10-14]. The fear of hypoglycemia and weight gain may promote suboptimal dosing of insulin, which may lead to diabetic ketoacidosis, a fatal complication $[15,16]$, in patients with T1DM.

Therefore, researchers kept on finding potential adjunct medications to insulin treatment for better treatment strategies. In recent years, the off-label use of antidiabetes drugs
Corresponding author: Linong Ji (D) https://orcid.org/0000-0002-3262-2168 Department of Endocrinology and Metabolism, Peking University People’s Hospital, No.11 Xizhimen South Street, Xicheng District, Beijing 100044, China

E-mail: prof_jilinong@aliyun.com
This is an Open Access article distributed under the terms of the Creative Commons Attribution Non-Commercial License (https://creativecommons.org/licenses/by-nc/4.0/) which permits unrestricted non-commercial use, distribution, and reproduction in any medium, provided the original work is properly cited. 
treating type 2 diabetes mellitus (T2DM) was given to patients with T1DM, since it was expected that the addition of non-insulin therapies might help patients with T1DM to achieve better glycemic control with possible reduction in hypoglycemia, body weight, insulin dose, and glucose variability. Several clinical trials and meta-analysis were done to show the efficacy and safety of these drugs such as glucagon-like peptide-1 receptor agonist (GLP-1RA), dipeptidyl peptide 4 inhibitor (DPP-4i), sodium glucose cotransporter 2 inhibitor (SGLT-2i), metformin, thiazolidinedione (TZD), and alpha glucosidase inhibitors (AGI), as add-on therapy with insulin. However, comprehensive evaluations of these drugs in terms of glycemic control, body weight control, as well as the risk of adverse effects and comparisons among different kinds of drugs were not well studied yet. Therefore, the aim of this meta-analysis was to evaluate the efficacy and side effects of these off-label used medications as an adjunct treatment to insulin in patients with T1DM.

\section{METHODS}

\section{Study design}

A systematic review with meta-analysis was conducted by using a prespecified study protocol which was registered in International Prospective Register of Systematic Reviews (PROSPERO) and traced with CRD42018095253. Analyses were conducted according to the Preferred Reporting Items for Systematic Reviews and Meta-Analyses (PRISMA) guidelines for conducting and reporting meta-analyses of randomized controlled trials (RCTs).

\section{Search strategy}

RCTs publicly available by March 2020, evaluating the effects of additional non-insulin antidiabetes drug in T1DM patients were included. The MEDLINE, EMBASE, and the Cochrane Central Register of Controlled Trials (CENTRAL) were searched using a highly sensitive search. Database specific subject headings (such as MeSH terms) and free texts terms were used to search for potentially eligible studies. The free texts including the following terms: metformin, acarbose, volglibose, miglitol, rosiglitazone, pioglitazone, exenatide, liraglutide, lixisenatide, dulaglutide, albiglutide, taspoglutide, semaglutide, sitagliptin, saxagliptin, vildagliptin, linagliptin, alogliptin, trelagliptin, teneligliptin, omarigliptin, dapagliflozin, canagliflozin, empagliflozin, ipragliflozin, tofogliflozin, luseogliflozin, ertugli- flozin, remogliflozin, sotagliflozin, pramlintide. ClinicalTrials. gov was also searched to identify additional eligible clinical trials and confirmed relevant data for all eligible published trials.

\section{Study selection and data extraction}

Double blind and placebo controlled RCTs evaluating the adjunction treatment of a non-insulin antidiabetes medications in T1DM were included. Studies evaluating treatment with single armed trials, active controlled trials, observational studies, retrospective studies, trials in T2DM and trials with study length less than 4 weeks were all excluded.

Two review authors (L.N. and W.Y.) independently and in duplicate screened titles/abstracts and full texts for eligible trials, assessed risk of bias and extracted the following data from each publication using a standardized form: publication data (title, first author, year, and source of publication), study design, baseline characteristics of the study population (sample size, gender, age, duration of T1DM, body mass index, and glycosylated hemoglobin [HbAlc]), description of the study drugs and the dosages and treatment duration. Primary outcomes were measured as change from baseline to study endpoint for HbA1c, risk of hypoglycemia. Secondary outcomes were measured as fasting plasma glucose (FPG) and postprandial plasma glucose (PPG) changes from baseline, body weight change from baseline, the risk of severe hypoglycemia, risk of nocturnal hypoglycemia, and risk of other side effects. Disagreements or discrepancies were resolved by discussion among the two review authors and a third investigator (X.C.). If a published trial did not report the relevant outcomes, the registry report data from ClinicalTrials.gov would be abstracted and used.

\section{Assessment of risk of bias}

Two reviewers independently assessed risk of bias for each trial using the Cochrane Collaboration tool. Each RCT was rated as having a low, high, or unclear risk of bias for the following aspects: sequence generation, allocation concealment, blinding of participants and personnel, blinding of outcome assessors, incomplete outcome data, selective outcome reporting, and other sources of bias.

\section{Statistical analysis}

The meta-analysis was performed by computing the weighted mean difference (WMD) and 95\% confidence intervals (CIs) to evaluate the changes of $\mathrm{HbAlc}$, FPG, PPG from baseline for 
the treatment of each antidiabetes drug group. The risk of hypoglycemia, the risk of severe hypoglycemia, risk of ketoacidosis and the risks of other side effects were expressed in relative risk (RR) or odds ratio (OR) and $95 \%$ CIs. A $P<0.05$ was considered statistically significant for all analyses. The betweenstudy heterogeneity was distributed as the chi-square statistics. $I^{2}$ statistics was used to quantify the percentage of total variation across studies that was attributable to heterogeneity rather than to chance. If the $I^{2}$ was $>50 \%$ indicating significant heterogeneity, a random-effects model was used; otherwise, a fixed-effects model was used. Publication bias was assessed via a visual inspection of the funnel plot. Sensitivity analysis was performed by including and excluding the low-level studies or the small sample sizes (less than 20 participants). Subgroup analysis was made according to the class of antidiabetes agents or according to the type of RCTs. All statistical analyses were performed with the STATA statistical software package version 13.1 (Stata Corp, College Station, TX, USA) and the Review Manager statistical software package version 5.3 (Nordic Cochrane Centre, Copenhagen, Denmark).

\section{RESULTS}

\section{Characteristics and methodological quality of included studies}

Overall, 57 studies were included in the meta-analysis in T1DM with antidiabetes agents in adjunct to insulin treatment (Fig. 1). Among these studies, 14 studies compared metformin with placebo in adjunct to insulin treatment, seven studies compared AGI with placebo, five studies compared TZD with placebo, six studies compared GLP-1RA with placebo, six studies compared DPP-4i with placebo, 13 studies compared SGLT-2i, and six studies compared pramlintide with placebo in adjunct to insulin treatment (Supplementary Table 1).

Overall, the risk of bias was high or unclear for random sequence generation in 32 trials (55.2\%); concealment of treatment allocation in 29 trials (50.0\%); masking of participants, masking of investigators, or both in 0 trials $(0.0 \%)$; masking of outcome assessment in 0 trials $(0.0 \%)$; completeness of outcome reporting in five trials (8.6\%); and selective reporting of outcomes in one trial (1.7\%) (Supplementary Table 2). The visual inspection of the funnel plots indicated an even distribution of the variables.

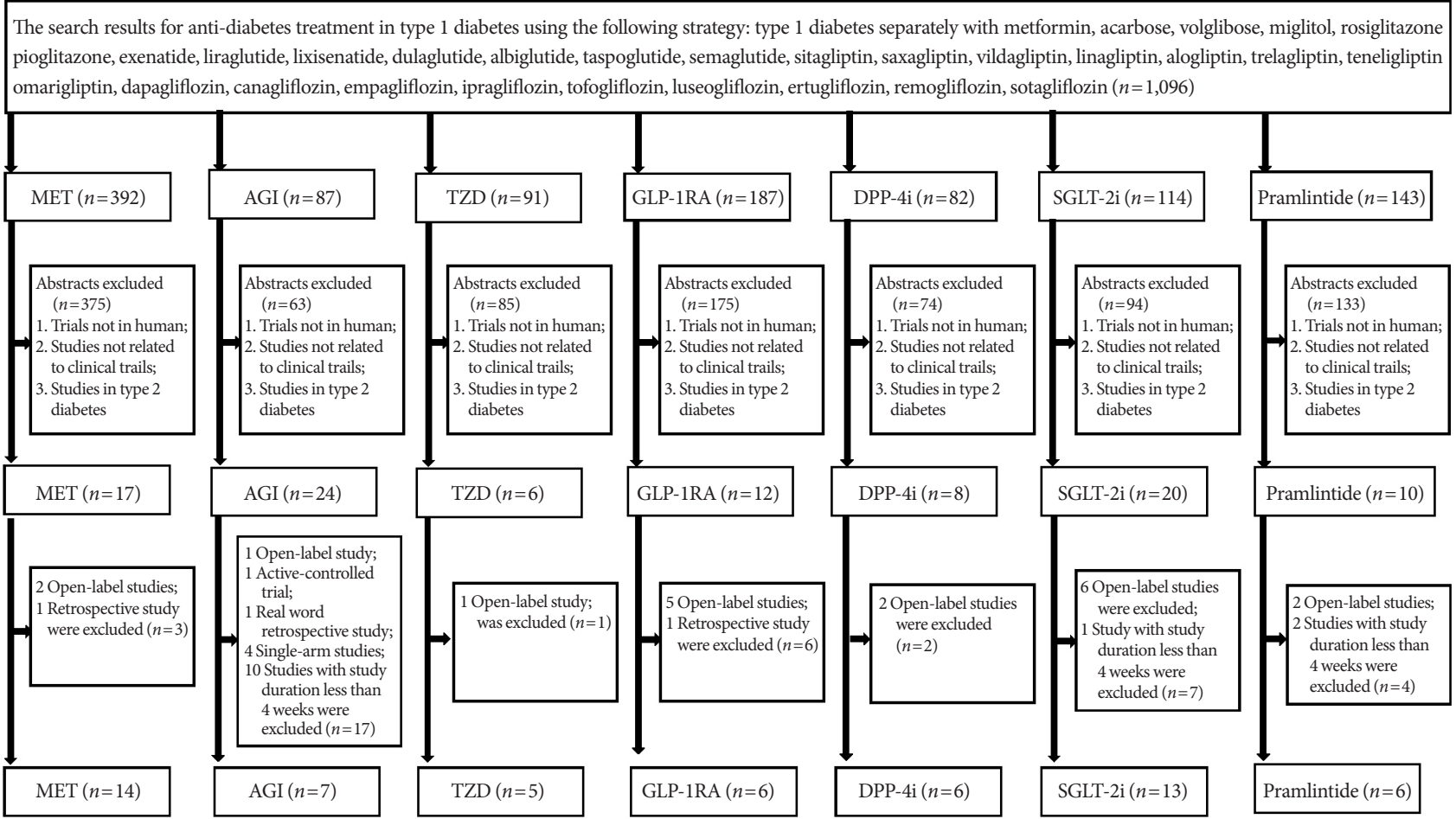

Fig. 1. Flow diagram of the included studies. MET, metformin; AGI, alpha glucosidase inhibitor; TZD, thiazolidinedione; GLP-1RA, glucagon-like peptide-1 receptor agonist; DPP-4i, dipeptidyl peptide 4 inhibitor; SGLT-2i, sodium glucose cotransporter 2 inhibitor. 


\section{Glycemic control and weight control}

Overall, compared with placebo, antidiabetes agents in adjunct to insulin treatment resulted in significant reduction in $\mathrm{HbAlc}$ (WMD, $-0.32 \%$; $95 \% \mathrm{CI},-0.36 \%$ to $-0.28 \% ; P<0.01$ ) and body weight (WMD, $-2.17 \mathrm{~kg} ; 95 \% \mathrm{CI},-2.78$ to $-1.57 \mathrm{~kg} ; P<0.01$ ). Compared with placebo, metformin exhibited significant reduction in HbAlc (WMD, $-0.29 \%$; $95 \%$ CI, $-0.50 \%$ to $-0.08 \%$; $P<0.01$ ) and body weight (WMD, $-2.08 \mathrm{~kg} ; 95 \% \mathrm{CI},-2.84$ to $-1.33 \mathrm{~kg} ; P<0.01)$, AGI led to significant reduction in HbAlc (WMD, $-0.58 \%$; $95 \% \mathrm{CI},-0.82 \%$ to $-0.33 \%$; $P<0.01$ ) but not in body weight (WMD, $0.9 \mathrm{~kg} ; 95 \% \mathrm{CI},-0.67$ to $2.47 \mathrm{~kg} ; P=$ 0.26), TZD resulted in non-significant increases in HbA1c (WMD, $0.05 \%$; $95 \%$ CI, $-0.33 \%$ to $0.42 \% ; P=0.81$ ) and body weight (WMD, $0.99 \mathrm{~kg} ; 95 \% \mathrm{CI},-1.10$ to $3.09 \mathrm{~kg} ; P=0.35$ ), DPP-4i led to non-significant reduction in HbA1c (WMD,
$-0.15 \%$; $95 \% \mathrm{CI},-0.34 \%$ to $0.04 \% ; P=0.13)$, and body weight (WMD, $0.1 \mathrm{~kg}$; $95 \% \mathrm{CI},-0.94$ to $1.14 \mathrm{~kg} ; P=0.85$ ), GLP-1RA contributed to significant reduction in HbA1c (WMD, $-0.19 \%$; 95\% CI, $-0.29 \%$ to $-0.1 \% ; P<0.01$ ) as well as in body weight (WMD, $-4.76 \mathrm{~kg}$; $95 \% \mathrm{CI},-4.95$ to $4.57 \mathrm{~kg} ; P<0.01$ ), SGLT-2i conferred significant reduction in $\mathrm{HbA1c}$ (WMD, $-0.42 \%$; $95 \%$ $\mathrm{CI},-0.47 \%$ to $-0.37 \% ; P<0.01$ ) and body weight (WMD, -2.70 $\mathrm{kg}$; $95 \% \mathrm{CI},-3.15$ to $-2.25 \mathrm{~kg}$; $P<0.01)$, pramlintide resulted in significant reduction in HbAlc (WMD, $-0.26 \%$; 95\% CI, $-0.41 \%$ to $-0.11 \%$; $P<0.01$ ), but not in body weight (WMD, $-1.18 \mathrm{~kg}$; $95 \%$ CI, -2.31 to $-0.04 \mathrm{~kg} ; P=0.04$ ) (Table 1, Fig. 2, and Supplementary Fig. 1).

\section{Dosage of insulin}

Compared with placebo, in adjunct to insulin treatment, anti-

Table 1. Comparisons between antidiabetes drugs and placebo as an adjunct treatment to insulin in T1DM patients in terms of HbAlc changes, weight changes, blood pressure changes, and dosage of insulin changes

\begin{tabular}{|c|c|c|c|c|c|c|}
\hline Comparison group & $\begin{array}{l}\text { Included } \\
\text { studies }\end{array}$ & $\begin{array}{l}\text { No. of patients } \\
\text { (antidiabetes } \\
\text { drugs/placebo) }\end{array}$ & WMD & $95 \%$ CI & $P$ value & $I^{2}, \%$ \\
\hline \multicolumn{7}{|l|}{ HbAlc change, \% } \\
\hline MET & 14 & $601 / 584$ & -0.29 & -0.50 to -0.08 & $<0.01$ & 98 \\
\hline AGI & 3 & $185 / 195$ & -0.58 & -0.82 to -0.33 & $<0.01$ & 98 \\
\hline TZD & 5 & 99/97 & 0.05 & -0.33 to 0.42 & 0.81 & 56 \\
\hline DPP-4i & 4 & $101 / 99$ & -0.15 & -0.34 to 0.04 & 0.13 & 45 \\
\hline GLP-1RA & 6 & $642 / 646$ & -0.19 & -0.29 to -0.1 & $<0.01$ & 95 \\
\hline SGLT-2i & 12 & $2,924 / 2,910$ & -0.42 & -0.47 to -0.37 & $<0.01$ & 99 \\
\hline Pramlintide & 5 & $997 / 888$ & -0.26 & -0.41 to -0.11 & $<0.01$ & 100 \\
\hline \multicolumn{7}{|l|}{ Weight change, kg } \\
\hline MET & 9 & $458 / 444$ & -2.08 & -2.84 to -1.33 & $<0.01$ & 96 \\
\hline AGI & 2 & $171 / 181$ & 0.9 & -0.67 to 2.47 & 0.26 & 100 \\
\hline TZD & 3 & $73 / 72$ & 0.99 & -1.10 to 3.09 & 0.35 & 0 \\
\hline DPP-4i & 2 & $77 / 76$ & 0.1 & -0.94 to 1.14 & 0.85 & 0 \\
\hline GLP-1RA & 6 & $642 / 646$ & -4.76 & -4.95 to -4.57 & $<0.01$ & 76 \\
\hline SGLT-2i & 12 & $2,441 / 2,433$ & -2.7 & -3.15 to -2.25 & $<0.01$ & 100 \\
\hline Pramlintide & 7 & $1,251 / 1,115$ & -1.18 & -2.31 to -0.04 & 0.04 & 100 \\
\hline \multicolumn{7}{|l|}{ FPG change, $\mathrm{mmol} / \mathrm{L}$} \\
\hline MET & 6 & $159 / 158$ & -0.96 & -2.49 to 0.57 & 0.22 & 94 \\
\hline AGI & 3 & $142 / 150$ & -1.75 & -2.25 to -1.24 & $<0.01$ & 79 \\
\hline TZD & 4 & $91 / 90$ & 0.04 & -0.45 to 0.54 & 0.87 & 0 \\
\hline DPP-4i & NA & NA & NA & NA & NA & NA \\
\hline GLP-1RA & 2 & $396 / 397$ & -0.12 & -0.22 to -0.01 & 0.03 & 0 \\
\hline SGLT-2i & 9 & $730 / 721$ & -1.05 & -1.24 to -0.86 & $<0.01$ & 91 \\
\hline Pramlintide & 1 & $19 / 19$ & 0.10 & -0.22 to 0.42 & 0.54 & NA \\
\hline
\end{tabular}

(Continued to the next page) 
Table 1. Continued

\begin{tabular}{|c|c|c|c|c|c|c|}
\hline Comparison group & $\begin{array}{c}\text { Included } \\
\text { studies }\end{array}$ & $\begin{array}{l}\text { No. of patients } \\
\text { (antidiabetes } \\
\text { drugs/placebo) }\end{array}$ & WMD & $95 \% \mathrm{CI}$ & $P$ value & $I^{2}, \%$ \\
\hline \multicolumn{7}{|l|}{ PPG change, $\mathrm{mmol} / \mathrm{L}$} \\
\hline MET & NA & NA & NA & NA & NA & NA \\
\hline AGI & 5 & $203 / 213$ & -1.97 & -2.69 to -1.26 & $<0.01$ & 76 \\
\hline TZD & 1 & $30 / 30$ & -0.21 & -0.84 to 0.42 & 0.51 & NA \\
\hline DPP-4i & NA & NA & NA & NA & NA & NA \\
\hline GLP-1RA & NA & NA & NA & NA & NA & NA \\
\hline SGLT-2i & NA & NA & NA & NA & NA & NA \\
\hline Pramlintide & 1 & $148 / 147$ & 0.50 & 0.27 to 0.73 & $<0.01$ & NA \\
\hline \multicolumn{7}{|c|}{ Insulin dosage change, unit/day } \\
\hline MET & 4 & $116 / 118$ & -4.83 & -7.10 to -2.56 & $<0.01$ & 66 \\
\hline AGI & 2 & $171 / 181$ & -0.55 & -5.15 to 4.06 & 0.82 & 100 \\
\hline TZD & 2 & $55 / 55$ & -0.20 & -3.43 to 3.04 & 0.90 & 0 \\
\hline DPP-4i & 2 & $77 / 76$ & -2.78 & -5.82 to 0.26 & 0.07 & 0 \\
\hline GLP-1RA & 6 & $642 / 688$ & -5.53 & -7.79 to -3.28 & $<0.01$ & 99 \\
\hline SGLT-2i & 7 & $1,633 / 1,632$ & -5.95 & -8.44 to -3.47 & $<0.01$ & 100 \\
\hline Pramlintide & 3 & $511 / 416$ & -8.25 & -12.24 to -4.26 & $<0.01$ & 99 \\
\hline \multicolumn{7}{|c|}{ Final insulin dosage, unit/day } \\
\hline MET & 4 & $116 / 118$ & -6.37 & -11.43 to -1.30 & 0.01 & 0 \\
\hline AGI & 2 & $71 / 73$ & -5.79 & -14.91 to 3.32 & 0.21 & 99 \\
\hline $\mathrm{TZD}$ & 2 & $55 / 55$ & -2.97 & -6.21 to 0.26 & 0.07 & 0 \\
\hline DPP-4i & 3 & $87 / 85$ & -4.07 & -7.07 to -1.06 & $<0.01$ & 0 \\
\hline GLP-1RA & 6 & $642 / 646$ & -4.71 & -6.72 to -2.70 & $<0.01$ & 97 \\
\hline SGLT-2i & 5 & $1,108 / 1,106$ & -5.69 & -11.79 to 0.41 & 0.07 & 93 \\
\hline Pramlintide & 3 & $511 / 416$ & -8.47 & -17.04 to 0.10 & 0.05 & 87 \\
\hline
\end{tabular}

T1DM, type 1 diabetes mellitus; HbA1c, glycosylated hemoglobin; WMD, weighted mean difference; CI, confidence interval; MET, metformin; AGI, alpha glucosidase inhibitor; TZD, thiazolidinedione; GLP-1RA, glucagon-like peptide-1 receptor agonist; DPP-4i, dipeptidyl peptide 4 inhibitor; SGLT-2i, sodium glucose cotransporter 2 inhibitor; FPG, fasting plasma glucose; NA, not available; PPG, postprandial plasma glucose.

diabetes agent treatment was associated with a more decreased dosage of insulin change from baseline (WMD, -5.17 unit/day; 95\% CI, -6.77 to -3.57 unit/day; $P<0.01)$. As for individual medications, treatment with metformin, GLP-1RA, SGLT-2i, or pramlintide, required a more decreased dosage of insulin change from baseline respectively (WMD -4.83,-5.53, -5.95,8.25 unit/day, respectively), while treatment with AGI, TZD, or DPP-4i did not show significant decrease in the dosage of insulin change from baseline (Table 1 and Supplementary Fig. 2).

Corrected by placebo effect, indirect comparisons between each two kinds of active antidiabetes agents in terms of HbAlc changes from baseline indicated significant difference between TZD versus SGLT-2i, which in favor of SGLT-2i treatment (mean difference [MD], 0.39; $P=0.003$ ), significant difference between GLP-1RA and SGLT-2i, which in favor of SGLT-2i treatment (MD, $0.22 ; P=0.012)$, and significant difference between DPP-4i and SGLT-2i, which also in favor of SGLT-2i treatment (MD, 0.28; $P=0.01)$ (Supplementary Table 3).

\section{Risk of hypoglycemia and other adverse effects}

Overall, in patients with T1DM, compared with placebo, in adjunct to insulin treatment, antidiabetes agent increased the risk of hypoglycemia (RR, 1.04; 95\% CI, 1.01 to $1.08 ; P=0.02$ ). Separately, treatment with metformin, AGI, TZD, GLP-1RA, DPP-4i, SGLT-2i, or pramlintide, did not increase the risk of hypoglycemia (Fig. 3). In terms of ketoacidosis, compared with placebo, the risk of ketoacidosis (RR, 3.44; 95\% CI, 2.01 to 5.89; $P<0.01)$ was increased in patients with active agent in ad- 


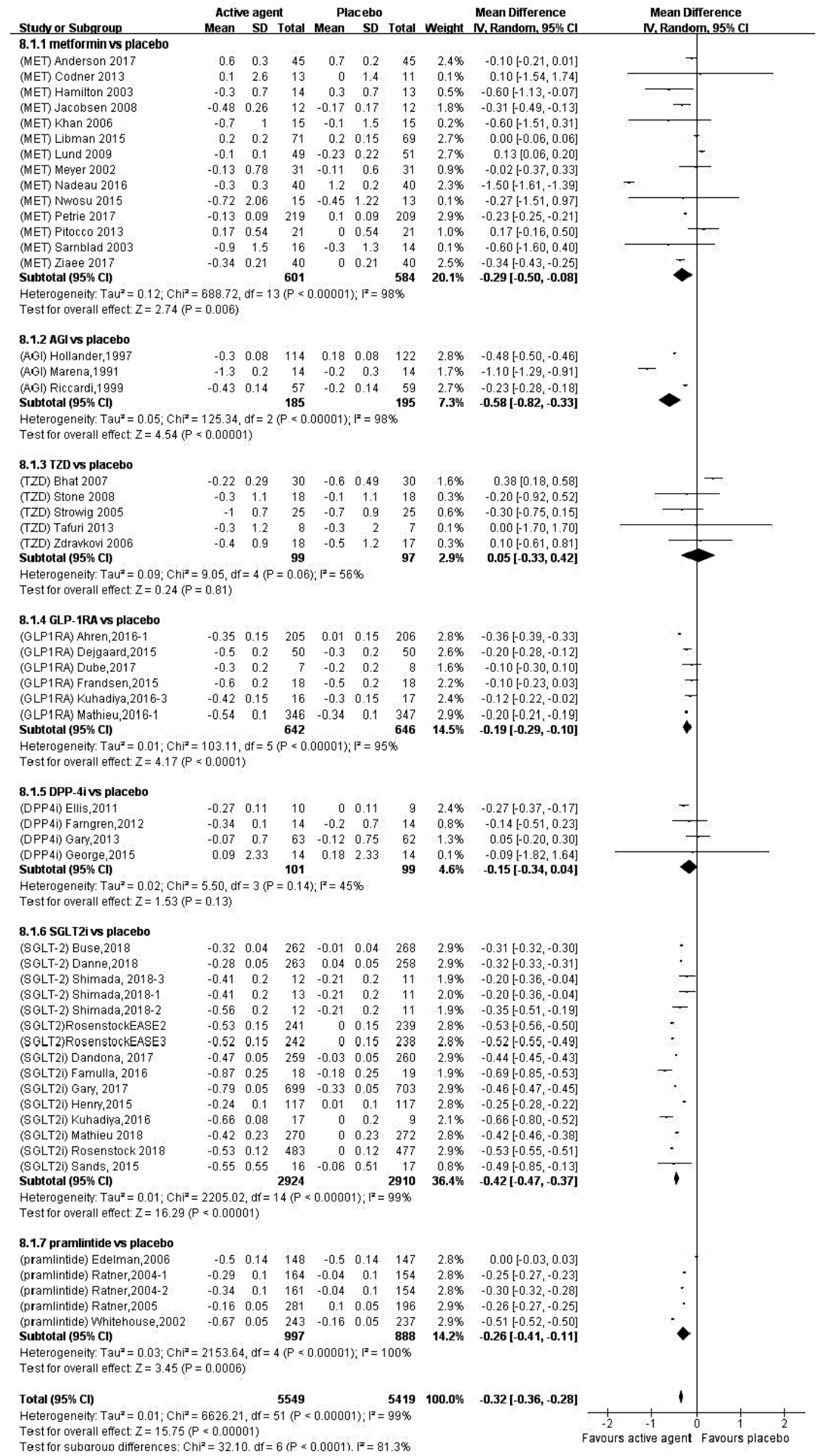

Fig. 2. Comparison of glycosylated hemoglobin (HbAlc) change from baseline between antidiabetes agent and placebo in patients with type 1 diabetes mellitus. SD, standard deviation; IV, inverse variance; CI, confidence interval; MET, metformin; AGI, alpha glucosidase inhibitor; TZD, thiazolidinedione; GLP-1RA, glucagon-like peptide-1 receptor agonist; DPP-4i, dipeptidyl peptide 4 inhibitor; SGLT-2i, sodium glucose cotransporter 2 inhibitor. 


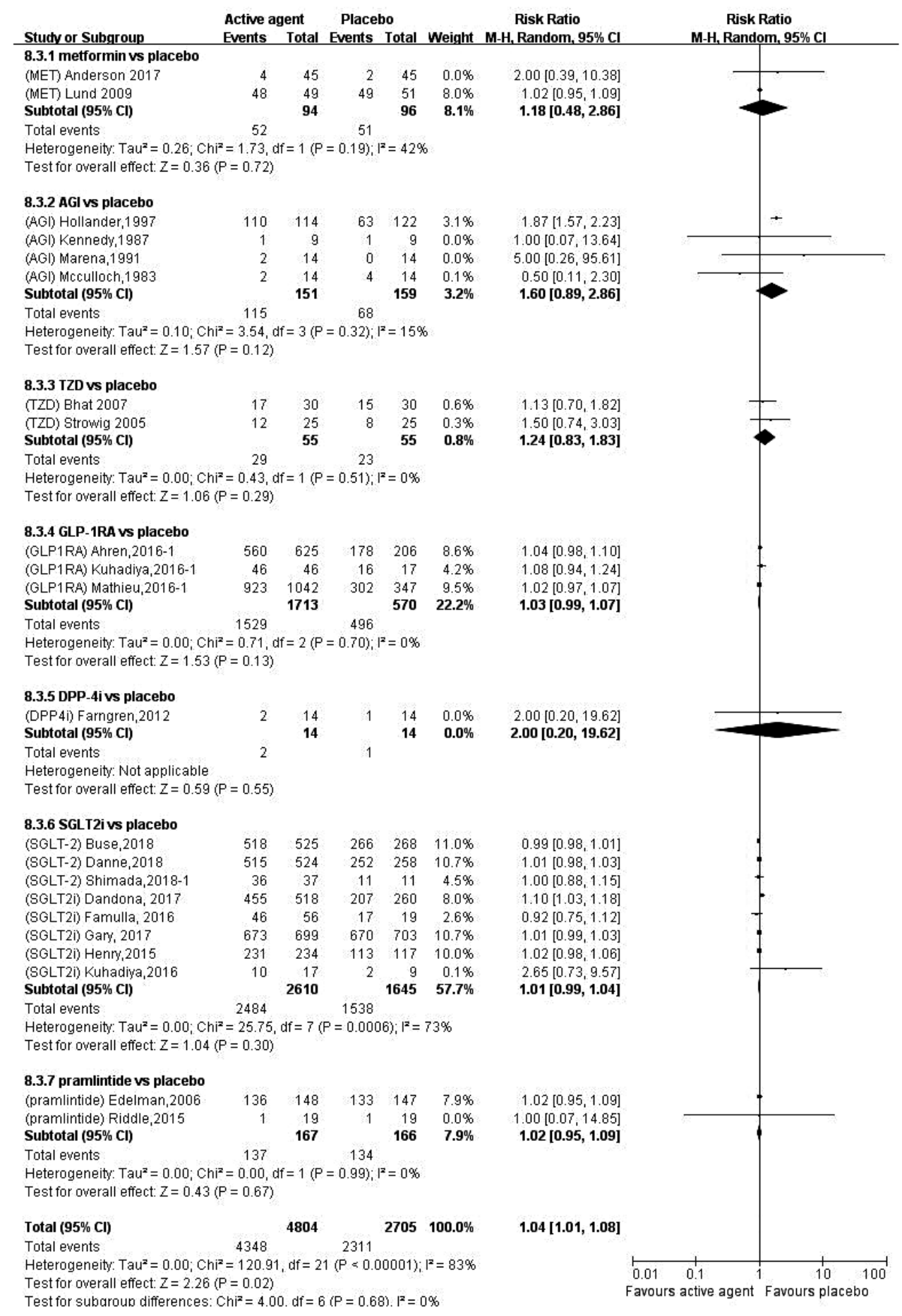

Fig. 3. Comparison of the risk of hypoglycemia between antidiabetes agent and placebo in patients with type 1 diabetes mellitus. W-H, Mantel-Haenszel; CI, confidence interval; MET, metformin; AGI, alpha glucosidase inhibitor; TZD, thiazolidinedione; GLP-1RA, glucagon-like peptide-1 receptor agonist; DPP-4i, dipeptidyl peptide 4 inhibitor; SGLT-2i, sodium glucose cotransporter 2 inhibitor. 
junct to insulin treatment. Separately, treatment with metformin or GLP-1RA, did not increase the risk of ketoacidosis, while treatment with SGLT-2i increased the risk of ketoacidosis (RR, 4.76; 95\% CI, 2.67 to 8.49; $P<0.01$ ) (Supplementary Fig. 3). There was no reported case of ketoacidosis with other antidiabetes treatments. As for gastrointestinal (GI) side effects, overall, compared with placebo, antidiabetes agent in ad- junct to insulin treatment increased the risk of GI side effects (RR, 1.99; 95\% CI, 1.61 to 2.46 ; $P<0.01$ ) (Supplementary Fig. 4). Separately, treatment with metformin, AGI, GLP-1RA, or pramlintide, did increase the risk of GI side effects (Table 2).

In total, the efficacy and safety features of each antidiabetes medication when used as an adjunct treatment to insulin in patients with T1DM were summarized in Table 3 . As is shown,

Table 2. Comparisons between antidiabetes drugs and placebo as an adjunct treatment to insulin in T1DM patients in terms of adverse effects

\begin{tabular}{|c|c|c|c|c|c|c|}
\hline Comparison group & $\begin{array}{l}\text { Included } \\
\text { studies }\end{array}$ & $\begin{array}{c}\text { No. of patients } \\
\text { (antidiabetes drugs/ } \\
\text { placebo) }\end{array}$ & Risk ratio & 95\% CI & $P$ value & $I^{2}, \%$ \\
\hline \multicolumn{7}{|l|}{ Hypoglycemia } \\
\hline MET & 2 & $94 / 96$ & 1.18 & $0.48-2.86$ & 0.72 & 42 \\
\hline AGI & 4 & $151 / 159$ & 1.60 & $0.89-2.86$ & 0.12 & 15 \\
\hline TZD & 2 & $55 / 55$ & 1.24 & $0.83-1.83$ & 0.29 & 0 \\
\hline DPP-4i & 1 & $14 / 14$ & 2.00 & $0.20-19.62$ & 0.55 & NA \\
\hline GLP-1RA & 3 & $1,713 / 570$ & 1.03 & $0.99-1.07$ & 0.13 & 0 \\
\hline SGLT-2i & 8 & $2,610 / 1,645$ & 1.01 & $0.99-1.04$ & 0.30 & 73 \\
\hline Pramlintide & 2 & $167 / 166$ & 1.02 & $0.95-1.09$ & 0.67 & 0 \\
\hline \multicolumn{7}{|l|}{ Severe hypoglycemia } \\
\hline MET & 5 & $180 / 177$ & 1.99 & $0.95-4.17$ & 0.07 & 31 \\
\hline AGI & 1 & $57 / 59$ & 3.10 & $0.13-74.64$ & 0.49 & NA \\
\hline TZD & 2 & $36 / 35$ & 0.65 & $0.11-3.80$ & 0.63 & 31 \\
\hline DPP-4i & 1 & $63 / 62$ & 0.33 & $0.01-7.90$ & 0.49 & NA \\
\hline GLP-1RA & 4 & $1,735 / 621$ & 0.80 & $0.58-1.10$ & 0.17 & 0 \\
\hline SGLT-2i & 5 & $2,500 / 1,606$ & 0.94 & $0.71-1.23$ & 0.64 & 26 \\
\hline Pramlintide & NA & NA & NA & NA & NA & NA \\
\hline \multicolumn{7}{|c|}{ Nocturnal hypoglycemia } \\
\hline MET & 1 & $15 / 13$ & 0.87 & $0.14-5.32$ & 0.88 & NA \\
\hline AGI & 1 & $14 / 14$ & 0.60 & $0.18-2.04$ & 0.41 & NA \\
\hline TZD & NA & NA & NA & NA & NA & NA \\
\hline DPP-4i & NA & NA & NA & NA & NA & NA \\
\hline GLP-1RA & 1 & $625 / 206$ & 1.00 & $0.88-1.14$ & 0.97 & NA \\
\hline SGLT-2i & 3 & $1,748 / 1,229$ & 0.97 & $0.95-1.00$ & 0.08 & 79 \\
\hline Pramlintide & NA & NA & NA & NA & NA & NA \\
\hline \multicolumn{7}{|l|}{ SAE } \\
\hline MET & 2 & $80 / 82$ & 0.37 & $0.16-0.85$ & 0.02 & NA \\
\hline AGI & NA & NA & NA & NA & NA & NA \\
\hline TZD & 3 & $61 / 60$ & 1.27 & $0.32-5.01$ & 0.73 & 22 \\
\hline DPP-4i & 1 & $63 / 62$ & 0.33 & $0.01-7.90$ & 0.49 & NA \\
\hline GLP-1RA & 5 & $1,735 / 621$ & 1.04 & $0.76-1.39$ & 0.80 & 7 \\
\hline SGLT-2i & 7 & $2,572 / 1,642$ & 1.68 & $1.30-2.16$ & $<0.01$ & 26 \\
\hline Pramlintide & NA & NA & NA & NA & NA & NA \\
\hline
\end{tabular}


Table 2. Continued

\begin{tabular}{|c|c|c|c|c|c|c|}
\hline Comparison group & $\begin{array}{l}\text { Included } \\
\text { studies }\end{array}$ & $\begin{array}{c}\text { No. of patients } \\
\text { (antidiabetes drugs/ } \\
\text { placebo) }\end{array}$ & Risk ratio & $95 \% \mathrm{CI}$ & $P$ value & $I^{2}, \%$ \\
\hline \multicolumn{7}{|c|}{ Discontinue due to $\mathrm{AE}$} \\
\hline MET & 2 & $120 / 120$ & 0.55 & $0.12-2.58$ & 0.45 & 0 \\
\hline AGI & 2 & $171 / 181$ & 5.32 & $2.28-12.43$ & $<0.01$ & 0 \\
\hline TZD & 2 & $43 / 42$ & 3.91 & $0.46-33.48$ & 0.21 & 0 \\
\hline DPP-4i & 2 & $77 / 76$ & 1.49 & $0.25-8.71$ & 0.66 & 33 \\
\hline GLP-1RA & 4 & $1,763 / 620$ & 4.14 & $2.48-6.92$ & $<0.01$ & 0 \\
\hline SGLT-2i & 6 & $2,517 / 1,622$ & 1.70 & $1.22-2.36$ & $<0.01$ & 30 \\
\hline Pramlintide & 2 & $429 / 343$ & 3.14 & $1.74-5.65$ & $<0.01$ & 0 \\
\hline \multicolumn{7}{|l|}{ Infection } \\
\hline MET & 2 & $64 / 64$ & 0.70 & $0.17-2.94$ & 0.63 & 0 \\
\hline AGI & 1 & $14 / 14$ & 0.33 & $0.01-7.55$ & 0.49 & NA \\
\hline TZD & NA & NA & NA & NA & NA & NA \\
\hline DPP-4i & 1 & $14 / 14$ & 0.57 & $0.21-1.52$ & 0.26 & NA \\
\hline GLP-1RA & 2 & $68 / 68$ & 1.13 & $0.45-2.84$ & 0.79 & 0 \\
\hline SGLT-2i & 9 & $2,627 / 1,661$ & 1.81 & $1.50-2.18$ & $<0.01$ & 44 \\
\hline Pramlintide & NA & NA & NA & NA & NA & NA \\
\hline \multicolumn{7}{|l|}{ GI side effects } \\
\hline MET & 11 & $525 / 510$ & 1.69 & $1.11-2.56$ & 0.01 & 72 \\
\hline AGI & 2 & $128 / 136$ & 2.83 & $2.01-3.97$ & $<0.01$ & 0 \\
\hline TZD & 1 & $18 / 18$ & 0.20 & $0.01-3.89$ & 0.29 & NA \\
\hline DPP-4i & NA & NA & NA & NA & NA & NA \\
\hline GLP-1RA & 5 & $1,781 / 638$ & 2.52 & $1.52-4.20$ & $<0.01$ & 86 \\
\hline SGLT-2i & 6 & $1,837 / 1,281$ & 1.41 & $0.83-2.39$ & 0.20 & 53 \\
\hline Pramlintide & 6 & $1,420 / 826$ & 2.53 & $1.70-3.74$ & $<0.01$ & 78 \\
\hline \multicolumn{7}{|l|}{ Ketoacidosis } \\
\hline MET & 4 & $180 / 178$ & 1.16 & $0.38-3.48$ & 0.80 & 0 \\
\hline AGI & NA & NA & NA & NA & NA & NA \\
\hline $\mathrm{TZD}$ & NA & NA & NA & NA & NA & NA \\
\hline DPP-4i & NA & NA & NA & NA & NA & NA \\
\hline GLP-1RA & 2 & $1,667 / 553$ & 2.44 & $0.29-20.54$ & 0.41 & 0 \\
\hline SGLT-2i & 7 & $2,533 / 1,888$ & 4.76 & $2.67-8.49$ & $<0.01$ & 0 \\
\hline Pramlintide & NA & NA & NA & NA & NA & NA \\
\hline
\end{tabular}

T1DM, type 1 diabetes mellitus; CI, confidence interval; MET, metformin; AGI, alpha glucosidase inhibitor; TZD, thiazolidinedione; DPP-4i, dipeptidyl peptide 4 inhibitor; GLP-1RA, glucagon-like peptide-1 receptor agonist; NA, not available; SGLT-2i, sodium glucose cotransporter 2 inhibitor; SAE, serious adverse event; AE, adverse event; GI, gastrointestinal.

compared with placebo, treatment with metformin decreased $\mathrm{HbAlc}$, body weight, insulin dosage and the risk of serious adverse event (SAE), but increased the risk of GI side effect. Compared with placebo, GLP-1RAs decreased HbA1c, body weight, FPG, and insulin dosage, but increased the risks of discontinue due to adverse event (AE) and GI side effect. Compared with placebo, SGLT2 inhibitors decreased HbA1c, body weight, FPG, and insulin dosage, but increased the risks of 
Table 3. Efficacy and safety for antidiabetes drugs as an adjunct treatment to insulin in T1DM patients

\begin{tabular}{|c|c|c|c|c|c|c|c|}
\hline Efficacy and safety & MET & AGI & TZD & DPP-4i & GLP-1RA & SGLT-2i & Pramlintide \\
\hline HbA1c change, $\%$ & Decreased & Decreased & Neutral & Neutral & Decreased & Decreased & Decreased \\
\hline Weight change, kg & Decreased & Neutral & Neutral & Neutral & Decreased & Decreased & Decreased \\
\hline FPG change, $\mathrm{mmol} / \mathrm{L}$ & Neutral & Decreased & Neutral & Not available & Decreased & Decreased & Neutral \\
\hline PPG change, $\mathrm{mmol} / \mathrm{L}$ & Not available & Decreased & Neutral & Not available & Not available & Not available & Increased \\
\hline Insulin dosage change, unit/day & Decreased & Neutral & Neutral & Neutral & Decreased & Decreased & Decreased \\
\hline Hypoglycemia & Neutral & Neutral & Neutral & Neutral & Neutral & Neutral & Neutral \\
\hline Severe hypoglycemia & Neutral & Neutral & Neutral & Neutral & Neutral & Neutral & Not available \\
\hline Nocturnal hypoglycemia & Neutral & Neutral & Not available & Not available & Neutral & Neutral & Not available \\
\hline SAE & Decreased & Not available & Neutral & Neutral & Neutral & Increased & Not available \\
\hline Discontinue due to $\mathrm{AE}$ & Neutral & Increased & Neutral & Neutral & Increased & Increased & Increased \\
\hline Infection & Neutral & Neutral & Not available & Neutral & Neutral & Increased & Not available \\
\hline GI side effects & Increased & Increased & Neutral & Not available & Increased & Neutral & Increased \\
\hline Ketoacidosis & Neutral & Not available & Not available & Not available & Neutral & Increased & Not available \\
\hline
\end{tabular}

T1DM, type 1 diabetes mellitus; MET, metformin; AGI, alpha glucosidase inhibitor; TZD, thiazolidinedione; DPP-4i, dipeptidyl peptide 4 inhibitor; GLP-1RA, glucagon-like peptide-1 receptor agonist; SGLT-2i, sodium glucose cotransporter 2 inhibitor; HbA1c, glycosylated hemoglobin; FPG, fasting plasma glucose; PPG, postprandial plasma glucose; SAE, serious adverse event; AE, adverse event; GI, gastrointestinal.

SAE, discontinue due to AE, infection, and ketoacidosis. Compared with placebo, pramlintide decreased $\mathrm{HbAlc}$, body weight, and insulin dosage, but increased the risks of discontinue due to $\mathrm{AE}$ and GI side effect.

\section{Subgroup analysis stratified by age}

Subgroup analysis of the management of T1DM between children or adolescents and adults indicated that in patients $\geq 18$ years old, compared with placebo group, $\mathrm{HbAlc}$ was decreased significantly (WMD, $-0.29 \%$; $95 \% \mathrm{CI},-0.33 \%$ to $-0.25 \%)$ in the antidiabetes treatment group, while in patients $<18$ years old, HbAlc changes were not significant between antidiabetes treatment and control groups. However, the between group variance test did not show any significant difference of WMD between patients $\geq 18$ years old and patients $<18$ years old $(P=0.80)$. In terms of body weight changes, insulin dosage changes, the risk of hypoglycemia, the risk of GI side effect and the risk of ketoacidosis, the variance tests did not show any significant difference of WMD between patients $\geq 18$ years old and patients with $<18$ years old either (Table 4 ).

\section{DISCUSSION}

It was well known that the factors as reduction in $\mathrm{HbAlc}$, improved weight control, decreasing in insulin doses, reduction in the risk of hypoglycemia and ketoacidosis were associated with improvements in common challenges with T1DM management $[17,18]$. This meta-analysis evaluated all these factors in T1DM with insulin treatment in combination with biguanides, AGIs, TZDs, GLP-1RA, DPP-4i, SGLT-2i, or pramlintide, which indicated that compared with placebo, most of these antidiabetes agents led to significant decrease in $\mathrm{HbAlc}$, dosage of insulin and body weight with increased risks of hypoglycemia and GI side effects.

In terms of improving glycemic control, it was expected that these adjunct treatments with antidiabetes drugs approved for the treatment of T2DM could also produce benefits in patients with T1DM, since tight glycemic control was demonstrated to have long-term positive effects on the development and progression of macro- and microvascular complications [6,7]. Results from our meta-analysis indicated that compared with placebo, antidiabetes agents as metformin, GLP-1RA, SGLT$2 \mathrm{i}, \mathrm{AGI}$, and pramlintide as adjunct therapy with insulin exhibited significant reductions in HbAlc in patients with T1DM, but not DPP-4i or TZD. It was suggested that the adjunct therapies with metformin, AGI, GLP-1RA, SGLT-2i, and pramlintide, by improving of insulin resistance, suppressing glucagon, delaying gastric emptying, and decreasing glucose absorption in both the gut and kidney, which are all potential targets in improving glucose control, might offer potential benefit in 
Table 4. Subgroup analysis of the management of T1DM between children or adolescents and adults

\begin{tabular}{|c|c|c|c|c|c|c|c|}
\hline Comparison group & $\begin{array}{l}\text { Included } \\
\text { studies }\end{array}$ & $\begin{array}{c}\text { No. of patients, } \\
\text { antidiabetes drugs/ } \\
\text { placebo }\end{array}$ & WMD & $95 \% \mathrm{CI}$ & $P$ value & $I^{2}, \%$ & $\begin{array}{l}P \text { value of group } \\
\text { difference }\end{array}$ \\
\hline HbAlc change, $\%$ & & & & & & & 0.80 \\
\hline$<18$ years old & 10 & $258 / 247$ & -0.36 & -0.88 to 0.17 & 0.18 & 98 & \\
\hline$\geq 18$ years old & 40 & $4,808 / 4,695$ & -0.29 & -0.33 to -0.25 & $<0.01$ & 99 & \\
\hline Weight change, kg & & & & & & & 0.38 \\
\hline$<18$ years old & 5 & $160 / 153$ & -1.11 & -3.54 to 1.32 & 0.37 & 48 & \\
\hline$\geq 18$ years old & 37 & $4,953 / 4,814$ & -2.24 & -2.86 to -1.61 & $<0.01$ & 100 & \\
\hline Insulin dosage change, unit/day & & & & & & & 0.51 \\
\hline$<18$ years old & 1 & $40 / 40$ & -8.5 & -18.44 to 1.44 & 0.09 & NA & \\
\hline$\geq 18$ years old & 25 & $3,205 / 3,126$ & -5.12 & -6.73 to -3.50 & $<0.01$ & 100 & \\
\hline Hypoglycemia & & & & & & & 0.79 \\
\hline$<18$ years old & 1 & $45 / 45$ & 2.1 & 0.36 to 12.08 & 0.41 & NA & \\
\hline$\geq 18$ years old & 21 & $4,759 / 2,660$ & 1.66 & 1.39 to 1.97 & $<0.01$ & 52 & \\
\hline GI side effects & & & & & & & 0.06 \\
\hline$<18$ years old & 7 & $218 / 212$ & 2.27 & 1.46 to 3.51 & $<0.01$ & 26 & \\
\hline$\geq 18$ years old & 24 & $5,709 / 3,197$ & 3.51 & 3.08 to 3.99 & $<0.01$ & 74 & \\
\hline Ketoacidosis & & & & & & & 0.10 \\
\hline$<18$ years old & 3 & $131 / 127$ & 1.63 & 0.49 to 5.41 & 0.42 & 0 & \\
\hline$\geq 18$ years old & 10 & $4,249 / 2,492$ & 4.96 & 2.94 to 8.37 & $<0.01$ & 5 & \\
\hline
\end{tabular}

T1DM, type 1 diabetes mellitus; WMD, weighted mean difference; CI, confidence interval; HbA1c, glycosylated hemoglobin; NA, not available; GI, gastrointestinal.

treating individuals with T1DM [19]. Several previously reported meta-analysis indicated that adding antidiabetes drugs could reduce $\mathrm{HbAlc}$ significantly but others did not show any improvement in HbAlc level [19-24].

In terms of hypoglycemia, which was found to be associated with intensive insulin therapy and was the most significant impediment to improve glycemic control in individuals with T1DM $[5,25,26]$, this meta-analysis showed that compared with placebo, the risk of hypoglycaemia was slightly increased in T1DM patients with the adjunct treatment of overall active agents but not with separate treatment of metformin, AGI, DPP-4i, GLP-1RA, TZD, SGLT-2i, or pramlintide although the glycemic control was improved. Ideally, the treatment for T1DM should improve HbAlc without increasing risk of hypoglycemia. What we found from this meta-analysis might gave us the promising results that by using these adjunct treatments separately with insulin treatment, patients with T1DM might get benefit from better glycemic control without increasing the risk of hypoglycemia.
Another concern was about the weight control in overweight individuals with T1DM. It was reported that the prevalence of overweight and obesity in T1DM individuals was increasing in parallel with the global population trends in weight gain [27-30], which might be related to over-insulinization, recurrent hypoglycemia and defensive snacking [31]. Therefore, to achieve body weight control target in T1DM patients, combination therapy using drugs with actions complementary to insulin could be appropriate [32]. According to our meta-analysis, it was suggested that compared with placebo, the adjunct treatment of metformin, GLP-1RA, SGLT-2i, and pramlintide could exhibit less weight gain in combination with insulin. Possible mechanisms for treatment of biguanides, GLP-1RA, SGLT-2i, and pramlintide realizing weight control in combination therapy with insulin might be similar as they acted for weight control in patients with T2DM.

Furthermore, adjunct therapies are expected to be helpful in the regard of decreasing the insulin dosage. In contrast, higher insulin doses and the use of intensive insulin therapy in pa- 
tients with T1DM were reported to be associated with increases in obesity and insulin resistance during the course of therapy [33], which was a complicating factor when intensive insulin management was attempted [34]. Results from this metaanalysis suggested that with the use of adjunct therapies of metformin, GLP-1RA, SGLT-2i, and pramlintide, compared to placebo, the insulin dose decreased a lot, but not for the treatment of AGI, DPP-4i, or TZD. This finding was in accordance with previous reports [19-24].

It was also expected that adjunct therapies might improve the risk of ketoacidosis in patients with T1DM, which is a lifethreatening AE. According to this meta-analysis, compared with placebo, the risk of ketoacidosis was significantly higher in patients with the adjunct therapies of SGLT-2i, but was not associated with the adjunct therapies of biguanides, or GLP1RA. Possible mechanisms for this increased risk of ketoacidosis might be associated with the euglycemic ketoacidosis that caused by using SGLT-2i.

In terms of other adverse effects, it was suggested by our meta-analysis that the risk of GI side effects was significantly higher with the adjunct therapies of biguanides, AGI, GLP1RA, and pramlintide, all of which were similar as reported in patients with T2DM using these kinds of antidiabetes drugs.

Since there are differences in the management of T1DM between children and adults, we conducted the subgroup analysis between children or adolescents and adults but did not find any significant difference between these two groups regarding the efficacy and safety of antidiabetes drugs. Moreover, we found that antidiabetes drugs did not affect $\mathrm{HbAlc}$ change, weight change, insulin dosage change, hypoglycemia, or ketoacidosis in pediatric T1DM patients, which might inspire us that the use of non-insulin antidiabetes drugs in pediatrics should be carefully evaluated, especially for patients with T1DM.

As a meta-analysis, this study has some limitations. Firstly, different types of studies with variable baseline characteristics of patients with T1DM were included in this meta-analysis, which might be associated with the heterogeneity between studies. We have performed sensitivity analyses according to different classes of active agents to control the bias. Secondly, the number of patients or the number of studies in some classes of active agent included in this meta-analysis was small, which might also be associated with the heterogeneity between studies. Another limitation was that we could not evaluate whether the cost-effectiveness or the quality of life was also improved directly by these data collected from RCTs, however, by improving glycemic control, weight control and reduction in insulin dosage, it was expected that the cost-effectiveness or the quality of life of patients with T1DM might be improved accordingly. Moreover, we were unable to report the improvement of insulin sensitivity or the changes in $\beta$-cell function in this meta-analysis because of the limited data.

But still, we have provided a comprehensive review of literature for the efficacy and safety of non-insulin antidiabetic medication in patients with T1DM, suggesting that metformin, GLP-1RAs, and SGLT2 inhibitors also resulted in reduction of glucose level, body weight, insulin dosage without increasing the risks of hypoglycemia and adverse effects, which might be promising treatment candidates for patients with T1DM. However, as the limited data for the efficacy of cardiovascular outcome and microvascular outcome, or the limited data for the cost-effectiveness evaluation, or the limited data for the evaluation of risk to benefit ratio, the use of these drugs in adjunct to insulin in T1DM patients has not been approved yet. Further research is needed to overcome the above limitations and outcome trials are needed to be carry out as those carried out in patients with T2DM to demonstrated the cardiovascular benefit and microvascular benefits.

\section{CONCLUSIONS}

Comparisons between the intriguing use of antidiabetes medications and placebo for T1DM from our meta-analysis showed that the use of antidiabetes medications in adjunction to insulin treatment could confer glycemic improvement, weight control and reduction in insulin dosage while might be associated with increased risks of hypoglycemia and GI side effects in patients with T1DM.

\section{SUPPLEMENTARY MATERIALS}

Supplementary materials related to this article can be found online at https://doi.org/10.4093/dmj.2020.0171.

\section{CONFLICTS OF INTEREST}

Linong Ji has received fees for lecture presentations from AstraZeneca, Merck, Novartis, Lilly, Roche, Sanofi-Aventis, and Takeda. Linong Ji has received consulting fees from companies including AstraZeneca, Merck, Novartis, Lilly, Roche, Sanofi- 
Aventis, and Takeda. Linong Ji has received grants/research support from AstraZeneca, Bristol-Myers Squibb, Merck, Novartis, and Sanofi-Aventis. There are no other disclosures for other authors.

\section{ORCID}

Xiaoling Cai https://orcid.org/0000-0002-7881-0543

Linong Ji https://orcid.org/0000-0002-3262-2168

\section{FUNDING}

This work was supported by National Key Research and Development Program of China (No. 2016YFC1304901), National Natural Science Foundation of China (No. 81970698 and No. 81970708) and Beijing Natural Science Foundation (No. 7202216). The funding agencies had no roles in the study design, data collection or analysis, decision to publish or preparation of the manuscript.

\section{ACKNOWLEDGMENTS}

We thank the doctors, nurses and technicians for their practical work during the study at Department of Endocrinology and Metabolism in Peking University People’s Hospital.

\section{REFERENCES}

1. Gepts W. Pathologic anatomy of the pancreas in juvenile diabetes mellitus. Diabetes 1965;14:619-33.

2. Dinneen S, Alzaid A, Turk D, Rizza R. Failure of glucagon suppression contributes to postprandial hyperglycaemia in IDDM. Diabetologia 1995;38:337-43.

3. Muller WA, Faloona GR, Aguilar-Parada E, Unger RH. Abnormal alpha-cell function in diabetes: response to carbohydrate and protein ingestion. N Engl J Med 1970;283:109-15.

4. Greenbaum CJ, Prigeon RL, D’Alessio DA. Impaired beta-cell function, incretin effect, and glucagon suppression in patients with type 1 diabetes who have normal fasting glucose. Diabetes 2002;51:951-7.

5. Diabetes Control and Complications Trial Research Group, Nathan DM, Genuth S, Lachin J, Cleary P, Crofford O, et al. The effect of intensive treatment of diabetes on the development and progression of long-term complications in insulindependent diabetes mellitus. N Engl J Med 1993;329:977-86.
6. Writing Team for the Diabetes Control and Complications Trial/Epidemiology of Diabetes Interventions and Complications Research Group. Sustained effect of intensive treatment of type 1 diabetes mellitus on development and progression of diabetic nephropathy: the Epidemiology of Diabetes Interventions and Complications (EDIC) study. JAMA 2003;290:2159-67.

7. Lachin JM, Orchard TJ, Nathan DM; DCCT/EDIC Research Group. Update on cardiovascular outcomes at 30 years of the diabetes control and complications trial/epidemiology of diabetes interventions and complications study. Diabetes Care 2014;37:39-43.

8. Luddeke HJ, Sreenan S, Aczel S, Maxeiner S, Yenigun M, Kozlovski P, et al. PREDICTIVE: a global, prospective observational study to evaluate insulin detemir treatment in types 1 and 2 diabetes: baseline characteristics and predictors of hypoglycaemia from the European cohort. Diabetes Obes Metab 2007;9:428-34.

9. Donnelly LA, Morris AD, Frier BM, Ellis JD, Donnan PT, Durrant $\mathrm{R}$, et al. Frequency and predictors of hypoglycaemia in type 1 and insulin-treated type 2 diabetes: a population-based study. Diabet Med 2005;22:749-55.

10. Chillaron JJ, Flores Le-Roux JA, Benaiges D, Pedro-Botet J. Type 1 diabetes, metabolic syndrome and cardiovascular risk. Metabolism 2014;63:181-7.

11. Rodrigues TC, Veyna AM, Haarhues MD, Kinney GL, Rewers $\mathrm{M}$, Snell-Bergeon JK. Obesity and coronary artery calcium in diabetes: the Coronary Artery Calcification in Type 1 Diabetes (CACTI) study. Diabetes Technol Ther 2011;13:991-6.

12. Pambianco G, Costacou T, Orchard TJ. The prediction of major outcomes of type 1 diabetes: a 12-year prospective evaluation of three separate definitions of the metabolic syndrome and their components and estimated glucose disposal rate: the Pittsburgh Epidemiology of Diabetes Complications Study experience. Diabetes Care 2007;30:1248-54.

13. Orchard TJ, Costacou T, Kretowski A, Nesto RW. Type 1 diabetes and coronary artery disease. Diabetes Care 2006;29:252838.

14. Purnell JQ, Dev RK, Steffes MW, Cleary PA, Palmer JP, Hirsch IB, et al. Relationship of family history of type 2 diabetes, hypoglycemia, and autoantibodies to weight gain and lipids with intensive and conventional therapy in the Diabetes Control and Complications Trial. Diabetes 2003;52:2623-9.

15. Frandsen CS, Dejgaard TF, Madsbad S. Non-insulin drugs to treat hyperglycaemia in type 1 diabetes mellitus. Lancet Diabetes Endocrinol 2016;4:766-80. 
16. Bode BW, Garg SK. The emerging role of adjunctive noninsulin antihyperglycemic therapy in the management of type $1 \mathrm{di}-$ abetes. Endocr Pract 2016;22:220-30.

17. Pettus J, Hirsch I, Edelman S. GLP-1 agonists in type 1 diabetes. Clin Immunol 2013;149:317-23.

18. Harris KB, Boland CL. Adjunctive role of glucagon-like peptide-1 receptor agonists in the management of type 1 diabetes mellitus. Pharmacotherapy 2016;36:1011-20.

19. Munir KM, Davis SN. The treatment of type 1 diabetes mellitus with agents approved for type 2 diabetes mellitus. Expert Opin Pharmacother 2015;16:2331-41.

20. Wang W, Liu H, Xiao S, Liu S, Li X, Yu P. Effects of insulin plus glucagon-like peptide-1 receptor agonists (GLP-1RAs) in treating type 1 diabetes mellitus: a systematic review and metaanalysis. Diabetes Ther 2017;8:727-38.

21. Guo H, Fang C, Huang Y, Pei Y, Chen L, Hu J. The efficacy and safety of DPP4 inhibitors in patients with type 1 diabetes: a systematic review and meta-analysis. Diabetes Res Clin Pract 2016;121:184-91.

22. Livingstone R, Boyle JG, Petrie JR; REMOVAL Study Team. A new perspective on metformin therapy in type 1 diabetes. Diabetologia 2017;60:1594-600.

23. Garg SK, Michels AW, Shah VN. Use of non-insulin therapies for type 1 diabetes. Diabetes Technol Ther 2013;15:901-8.

24. Chen J, Fan F, Wang JY, Long Y, Gao CL, Stanton RC, et al. The efficacy and safety of SGLT2 inhibitors for adjunctive treatment of type 1 diabetes: a systematic review and meta-analysis. Sci Rep 2017;7:44128.

25. Heller SR, Amiel SA, Mansell P. Effect of the fast-acting insulin analog lispro on the risk of nocturnal hypoglycemia during intensified insulin therapy. U.K. Lispro Study Group. Diabetes Care 1999;22:1607-11.

26. Adverse events and their association with treatment regimens in the diabetes control and complications trial. Diabetes Care 1995;18:1415-27.

27. Polsky S, Ellis SL. Obesity, insulin resistance, and type 1 diabetes mellitus. Curr Opin Endocrinol Diabetes Obes 2015;22: 277-82.

28. Libman IM, Pietropaolo M, Arslanian SA, LaPorte RE, Becker DJ. Changing prevalence of overweight children and adolescents at onset of insulin-treated diabetes. Diabetes Care 2003; 26:2871-5.

29. Liu LL, Lawrence JM, Davis C, Liese AD, Pettitt DJ, Pihoker C, et al. Prevalence of overweight and obesity in youth with diabetes in USA: the SEARCH for Diabetes in Youth study. Pediatr Diabetes 2010;11:4-11.

30. DuBose SN, Hermann JM, Tamborlane WV, Beck RW, Dost A, DiMeglio LA, et al. Obesity in youth with type 1 diabetes in Germany, Austria, and the United States. J Pediatr 2015;167: 627-32.

31. Klupa T. Metformin in type 1 diabetes mellitus?: revisiting treatment dogmas in diabetes. Pol Arch Med Wewn 2016;126: 461-2.

32. Priya G, Kalra S. A review of insulin resistance in type 1 diabetes: is there a place for adjunctive metformin? Diabetes Ther 2018;9:349-61.

33. Frohlich-Reiterer EE, Rosenbauer J, Bechtold-Dalla Pozza S, Hofer SE, Schober E, Holl RW, et al. Predictors of increasing BMI during the course of diabetes in children and adolescents with type 1 diabetes: data from the German/Austrian DPV multicentre survey. Arch Dis Child 2014;99:738-43.

34. Mortensen HB, Robertson KJ, Aanstoot HJ, Danne T, Holl RW, Hougaard P, et al. Insulin management and metabolic control of type 1 diabetes mellitus in childhood and adolescence in 18 countries. Hvidore Study Group on Childhood Diabetes. Diabet Med 1998;15:752-9. 